Article

\title{
Fragility Analysis of Gantry Crane Subjected to Near-Field Ground Motions
}

\author{
Qihui Peng ${ }^{1,2} \oplus$, Wenming Cheng ${ }^{1,2, *}$, Hongyu Jia ${ }^{3, *}$ and Peng Guo ${ }^{1,2}$ \\ 1 School of Mechanical Engineering, Southwest Jiaotong University, Chengdu 610031, China; \\ bk20100219@my.swjtu.edu.cn (Q.P.); Pengguo@my.swjtu.edu.cn (P.G.) \\ 2 Technology and Equipment of Rail Transit Operation and Maintenance Key Laboratory of Sichuan Province, \\ Chengdu 610031, China \\ 3 School of Civil Engineering, Southwest Jiaotong University, Chengdu 610031, China \\ * Correspondence: wmcheng@home.swjtu.edu.cn (W.C.); Hongyu1016@swjtu.edu.cn (H.J.)
}

Received: 23 May 2020; Accepted: 17 June 2020; Published: 19 June 2020

check for updates

\begin{abstract}
A gantry crane located in a near-field earthquake-prone area is selected in this paper as an example, and the nonlinear finite element $(\mathrm{FE})$ model is used considering the material nonlinearity including plastic hinges and the second order $(\mathrm{P}-\Delta)$ effect with a comprehensive consideration of the components including sill beams, support beams, legs, and trolley girders. The local displacement ratio (LDR) and deflection ratio (DR) are proposed as demand measures (DMs) of the gantry crane, which are utilized to construct a probabilistic seismic demand model (PSDM). Then, the capacity limit states for the gantry crane are defined in this study by performing pushover analysis (POA), known as serviceability, damage control, and collapse prevention, respectively. Moreover, the operating capacity of the crane during an earthquake is further investigated and quantified by operating seismic peak ground acceleration, which is defined as the maximum acceleration when the failure probability is $50 \%$. Finally, the fragility curves and the failure probability of the gantry crane are derived by the above definitions, all of which are pioneering in the seismic design of gantry cranes subjected to near-field ground motions. Some major conclusions are drawn that the horizontal component of an earthquake has a more notable effect on the structural damage of the gantry crane compared to the vertical component, and incremental dynamic analysis can take seismic uncertainty into account and quantify the deformation of gantry crane in more detail.
\end{abstract}

Keywords: gantry crane; incremental dynamic analysis; fragility analysis; seismic capacity; near-field ground motion

\section{Introduction}

A gantry crane is a special equipment widely utilized in ports and freight stations as one of the most significant components of the modern system. It is non-negligible in cargo transportation as a lifeline of goods and materials during and after a natural hazard especially the post-earthquake reconstruction. In recent years, there has been an increasing tendency in structure design to consider seismic safety and appreciate the estimation of the seismic performance of a structure, especially large infrastructure. Compared to traditional steel moment frames, the gantry crane has a larger span, bigger payload, and more complicated operating conditions; therefore, more efforts should be put into the seismic safety of gantry cranes. However, the seismic performance of the gantry crane has been largely disregarded compared with that of bridges and steel moment frames [1,2]. In fact, as the lifting capacity of the gantry cranes continue to increase [3], some research works suggested that many newer cranes may fail during earthquakes because of their larger gauge length and heavier loads $[4,5]$. The 1995 Kobe Earthquake indicated that the impact of the earthquake on the crane structures cannot 
be omitted (see Figure 1) and brought up that the cranes with better seismic-resistant behavior in modern logistics systems count for much.

In the past few decades, a few research works have been carried out in terms of the seismic behavior of container cranes. Dinevski et al. [6] first demonstrated the capability of a modern finite element method to capture the dynamic characteristics of a container crane structure. A series of studies in Japan was performed following the Kobe Earthquake [7-9], which was conducted decades ago. Jacobs and Kosbab et al. $[10,11]$ presented the results of the scale testing and analysis of a typical container crane subjected to earthquake loading. Li Zhe and Wang Gongxian investigated the dynamic behavior of a container crane subjected to multi-direction seismic load [12]. Furthermore, the active seismic control of crane structures has also been investigated based on the shock absorption theory. For example, Sagiril [13] developed a five degree-of-freedom mathematical model of a gantry crane to investigate the dynamic behaviors of cranes under seismic effects. Yazici and Oktay et al. [14-16] studied the active vibration control of container cranes against earthquakes by varies controllers. These studies have proven that active vibration control has a great potential in cranes for suppressing earthquake-induced vibration [17]. It is notable that all the above research work analyzed the seismic capacity of the cranes based on deterministic analysis (i.e., seismic analyses of the container crane subjected to one or more specific seismic records). For a more precise and reliable result, fragility analysis should be considered for the seismic valuation of the cranes. Fragility analysis is an operational and comparatively mature method [18-20], which is commonly utilized in conventional structures, such as steel moment-resisting frames [21,22] and bridges [23-25], to combine the seismic uncertainties and structural uncertainties in the seismic valuation.

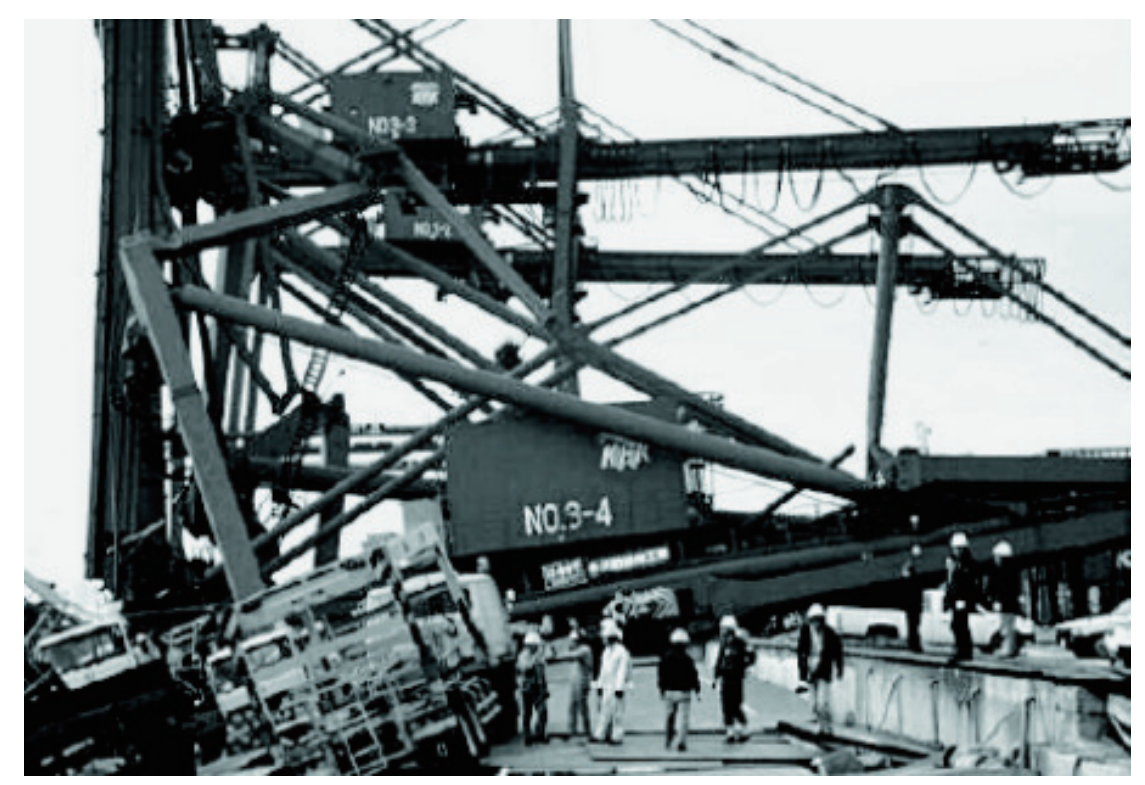

Figure 1. Collapsed cranes after the Kobe Earthquake [10].

Near-field ground motions are described by high velocity and long-period displacement pulses, which have a damaging potential and could result in more serious consequences compared to far-field seismic records [26]. However, to the best of the authors' knowledge, the fragility analysis of the gantry crane has not been reported so far, let alone subjected to near-field ground motions. Based on this situation, this study develops a probabilistic seismic demand model (PSDM) for the first time to further investigate the seismic fragility of a gantry crane and the influence of the seismic incident direction on the structural susceptibility. As mentioned above, the seismic and structural uncertainties should be considered for performance-based earthquake engineering [27], both of which have particular effects on the seismic behavior of the container crane. However, it has been discovered that the influence of seismic uncertainty on structural performance is much larger than that of structural uncertainty [28-30]. Given that fact, this paper only considers seismic uncertainty to simplify the fragility analysis of the 
container crane. Therefore, the structural material and geometric parameters in the finite element $(\mathrm{FE})$ model are deterministic and equal to their respective mean values.

Compared to bridges and steel moment frames, the structure of the gantry crane is relatively simple, but the payload of the gantry crane is relatively large with complicated working conditions. There mainly exist the following obvious differences when it comes to the seismic analysis of the gantry crane in this paper: (1) The seismic demand measures (DMs) are specified based on the structural characteristics of the gantry crane. As will be explained later, a new DM called the local displacement ratio (LDR) is proposed as the optimal DM to describe the seismic performance of the gantry crane more precisely. (2) The seismic operating capacity of the gantry crane is also investigated to assess the ability of the gantry crane to protect the crane operator and the lifted goods. (3) This research focuses on the fragility analysis of the gantry crane subjected to near-field ground motions. This paper is structured as: The original and FE models of a typical gantry crane are presented in Section 2. The probabilistic seismic demand model (PSDM) and five groups of limit states are defined for the gantry crane in Section 3. In Section 4, twenty near-field ground motions are selected for the fragility analysis. Fragility curves for the gantry crane subjected to ground motions under three different working conditions are developed in Section 5 , and the influence of the seismic incident direction on the structural susceptibility is also investigated. Besides, seismic valuation for the regular operation of the gantry crane is also investigated in this section. Finally, the significant conclusions and discussions of this research are presented in Section 6.

\section{Prototype and Finite Element Model}

\subsection{General Description}

A typical gantry crane located in a near-field earthquake-prone region is selected for the fragility analysis in this paper, and the procedure of fragility analysis is presented in detail in Figure 2. Firstly, suitable ground motions and a finite element model of the gantry crane should be developed. Then, nonlinear time-history analyses are carried out to obtain the structural response data of this model. Finally, fragility curves are developed after defining the limit states of this structure.

As shown in Figure 3, the gantry crane mainly contains two sill beams, two support beams, four legs (two flexible legs and two rigid legs, respectively), and two trolley girders, all of which are constructed with Q235 steel. The sample gantry crane has a total height of $15 \mathrm{~m}$ and a span of $35 \mathrm{~m}$.

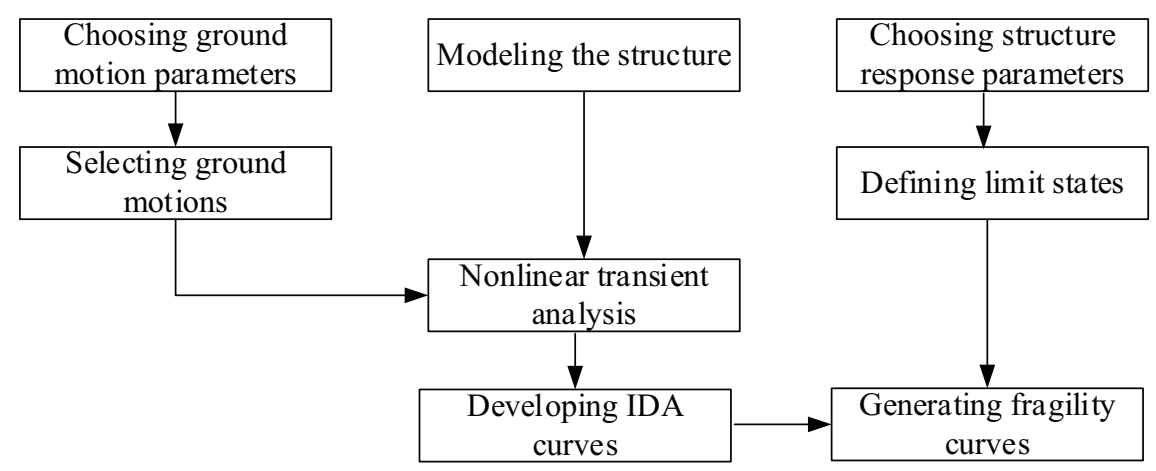

Figure 2. Flowchart of the seismic fragility analysis for the gantry crane using the increment dynamic analysis (IDA) method. 

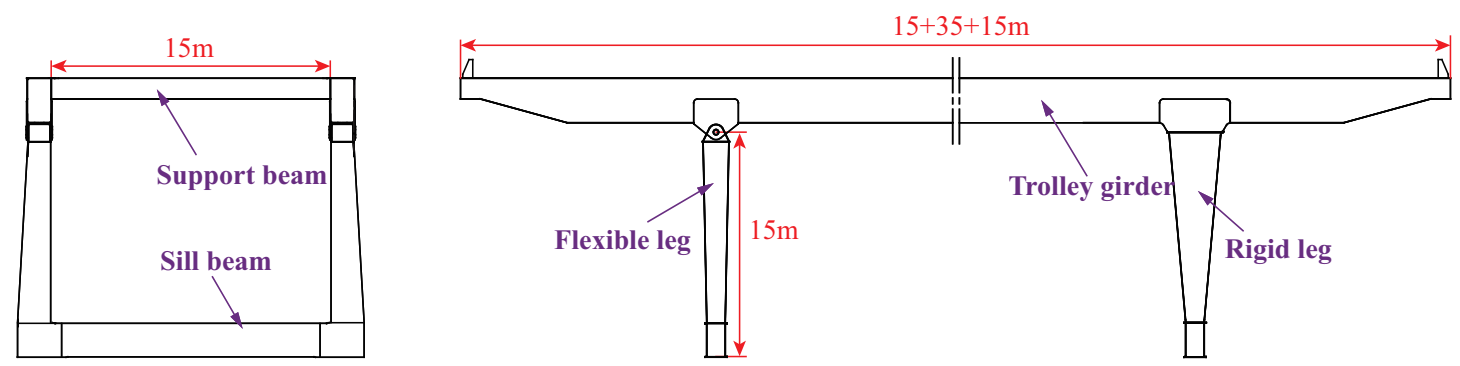

Figure 3. Schematic of the sample gantry crane.

\subsection{Finite Element Models}

The OpenSees software is an object-oriented, earthquake engineering software framework developed to offer researchers an analysis tool to analyze advanced structural and geotechnical systems [31,32]. Because of the versatile material and element libraries and the ability to control the solution procedures and algorithms [31,33], OpenSees was selected as the computational platform for the study. Based on the above information, the finite element (FE) model of the gantry crane was established in the OpenSees software, which is used to analyze advanced structural and geotechnical systems [31,32]. The schematic 3D model of the gantry crane is shown in Figure 4. The blue points in this model play an important role in the definition of the variable section parameters of beams and columns as reference points. Since the section parameters of the columns varied with length, the gap between two reference points on columns was relatively small to construct the columns more accurately. The black lines between two points are the nonlinear columns and beams used to simulate the structure of the gantry crane. Moreover, a centerline approximation was applied, and the effect of the panel zone was neglected since the extra flexibility introduced to the system due to centerline dimensions counteracted the influence of the omission of the panel zone [11]. Besides, the second-order $(\mathrm{P}-\Delta)$ effect was considered in this case to take geometric non-linearity into account, the influence of which was too remarkable to ignore since the nonlinear deformation or permanent deformation of the structure would increase dramatically [34]. Furthermore, the elastic modulus, mass density, the yield stress of Q235 steel, and the damping ratio were respectively equal to $2.01 \times 10^{11} \mathrm{~Pa}, 7800 \mathrm{~kg} / \mathrm{m}^{3}$, $235 \mathrm{MPa}$, and 3\%. It is worth noting that the trolley-travel direction, vertical direction, and the gantry-travel direction was correspondingly described as the $\mathrm{X}, \mathrm{Y}$, and $\mathrm{Z}$ coordinates, respectively (see Figure 4).

In addition, the junctions where trolley beams and legs were connected were modeled as rotational springs to simulate plastic hinges, which was an efficient way to define the nonlinear behavior of the joints. A schematic of the spring model and constitutive model of the spring i shown in Figures 5 and 6 . In previous studies [10], the joints between columns and rows were simulated with plastic hinges as well, but the rows were considered elastic given the relatively small span of rows and less computational effort. However, this strategy could not be applied in this research since the span of the girder $(35 \mathrm{~m})$ was too long to ignore its nonlinear behavior during an earthquake. Hence, all the columns and rows were considered as nonlinear elements, which were achieved by the dispBeamColumn element along the length of the element and the Aggregator section in OpenSees.

According to FEMA356 [35], the moment versus rotation curve model is established in Figure 6. Linear response is shown between Point A and Yield Point B. The slope from B to C of $1 \%$ was chosen in this research as an appropriate percentage of the plastic slope. $C$ represented the beginning of a considerable strength degradation. Beyond Point $\mathrm{D}$, the component responded with significantly reduced strength to Point E. Finally, the strength was basically zero beyond Point E. [35]. Table 1 shows the material and section properties of the gantry crane's components. They were used to determine the values of $a, b$, and $c$ as characteristic parameters. The section properties were variable for the flexible and rigid legs, which were chosen near the joints connected with girders. Based on FEMA356 and Table $1, a=4 \beta_{y}, b=6 \beta_{y}$, and $c=0.2 M_{y}$, respectively. 


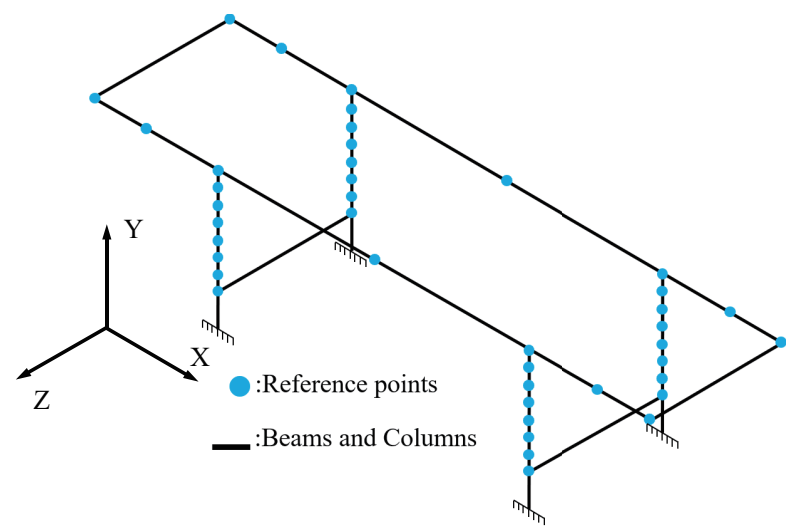

Figure 4. 3D model of the gantry crane.

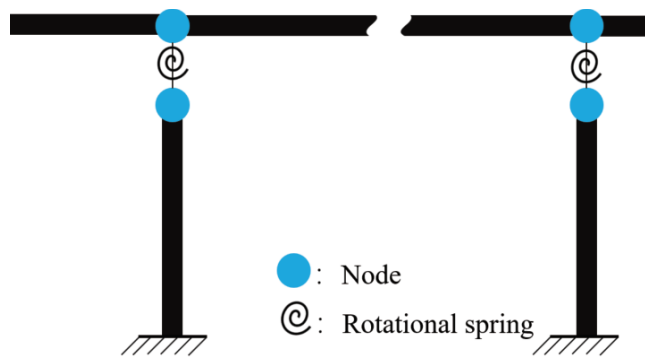

Figure 5. Spring model of the structure.

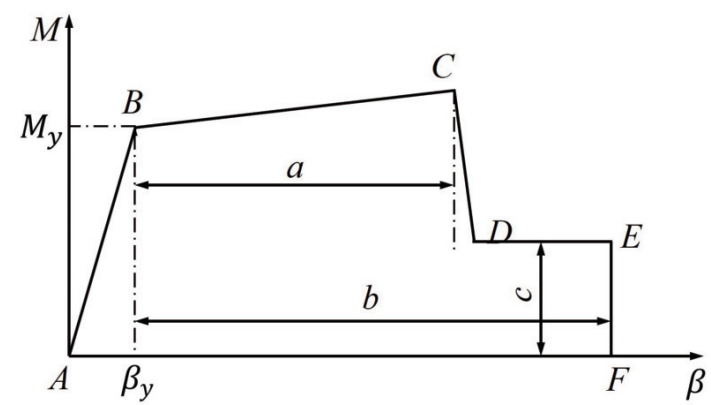

Figure 6. Constitutive model of the spring.

Table 1. Section properties of the gantry crane.

\begin{tabular}{lllll}
\hline Parameters & Trolley Girder & Flexible Leg & Rigid Leg & Description \\
\hline$b_{\mathrm{f}}(\mathrm{mm})$ & 1535 & 1333 & 3000 & Width of flange slab \\
$t_{\mathrm{f}}(\mathrm{mm})$ & 14 & 8 & 10 & Thickness of flange slab \\
$F_{\mathrm{y}}(\mathrm{MPa})$ & 235 & 235 & 235 & Yield stress of steel \\
$h(\mathrm{~mm})$ & 1987 & 1258 & 1500 & Distance between two flange slabs \\
$t_{\mathrm{w}}(\mathrm{mm})$ & 10 & 10 & 10 & Thickness of web slab \\
\hline
\end{tabular}

\section{Probabilistic Seismic Demand Model and Definition of Limit States}

\subsection{Probabilistic Seismic Demand Model}

As stated above, the seismic fragility analysis of steel moment-resisting frames (SMRF) has been studied for a long time, and various methods have been proposed to form the fragility curves of the structure. In this paper, the method proposed by Cornell et al. [36] was used to develop the fragility curves of the gantry crane. The seismic demands were deemed to obey a logarithmic normal distribution in this method. Hence, the fragility description can be written as: 


$$
P(D \geq d \mid I M)=1-\phi\left(\frac{\ln (d)-\ln \left(S_{D}\right)}{\beta_{D \mid I M}}\right)
$$

in which,

$\phi(\cdot)=$ the standard normal cumulative distribution function;

$D=$ the structural demand;

$d=$ the specified threshold values for different limit states;

$S_{D}=$ the median value of the structural demand in terms of a seismic intensity measure;

$\beta_{D \mid I M}=$ the logarithmic standard deviation.

In light of [36,37], the association between $S_{D}$ and the intensity measure (IM) can be described as a power model:

$$
S_{D}=a I M^{b}
$$

To complete a linear regression analysis, the above equation is generally revised as follows:

$$
\ln \left(S_{D}\right)=b \ln (I M)+c
$$

where $b$ and $c$ are the coefficients acquired by regression analysis.

The raw statistics used to form fragility curves were acquired by performing increment dynamic analyses (IDAs). Then, $S_{D}$, the median value of the structural demand in terms of a seismic intensity measure, and $\beta_{D \mid I M}$, the logarithmic standard deviation, could be calculated for each analysis. $\beta_{D \mid I M}$ can be calculated by the following equation:

$$
\beta_{D \mid I M} \cong \sqrt{\frac{\sum\left(\ln \left(d_{i}\right)-\ln \left(a I M^{b}\right)\right)^{2}}{N-2}}
$$

in which $d_{i}$ is the $i^{\text {th }}$ seismic demand from the non-linear time history analyses and $N$ represents the number of total simulation cases, which was twenty in this research.

\subsection{Definition of Limit States}

After developing the PSDM, intensity measures (IMs) and demand measures (DMs) need to be defined for the PSDM of the gantry crane. Though there was no previous research investigating the fragility curves of the gantry crane, researchers in other fields have made great effort to select the optimal IMs and DMs. The normally used IMs are spectral velocity $\left(\mathrm{S}_{\mathrm{v}}\right)$, peak ground acceleration (PGA), spectral acceleration $\left(S_{a}\right)$ at the fundamental period [38,39], etc. In this paper, the direct, and convenient IM, PGA, was selected as the IM of the gantry crane for a preliminary analysis. Different from the conventional steel frame, the gantry crane needs to be operated under variable working conditions. To simplify the calculation of the limit states, three major working conditions were considered: fully-loaded trolley located in the midspan of the girder, fully-loaded trolley located in the cantilever beam close to the flexible legs, and fully-loaded trolley located in the cantilever beam close to the rigid legs, respectively. For a more convenient description, the three conditions are called Case 1, Case 2, and Case 3 below.

As for DMs, many parameters have been used to create the fragility curves of structures. These are peak inter-story drift [40-42], the maximum base shear [43], peak roof drift [44], etc. Due to the special structure shape of the gantry crane, all of the DMs mentioned above could not be directly utilized in the study of the gantry crane. Considering that the inter-story drift of the structure showed a better correlation with the level of structural damage, a new DM called the local displacement ratio (LDR) of the gantry crane was proposed for the first time based on the inter-story drift as follows: 


$$
L D R=\left\{\begin{array}{c}
\frac{\Delta x}{h}, \\
\frac{\Delta y_{g}}{L_{g}}, \\
\frac{\Delta y_{c}}{L_{c}}
\end{array}\right.
$$

in which,

$\Delta x=$ displacement of the joint of the leg and the girder in the X-direction.

$h=$ height of the leg.

$\Delta y_{g}=$ displacement of the girder in the Y-direction.

$L_{g}=$ length of the girder.

$\Delta y_{c}=$ displacement at the valid cantilever end in the Y-direction.

$L_{c}=$ length of the valid cantilever.

According to the operating conditions of the gantry crane, four groups of thresholds should be determined. Besides, the deflection of the trolley girder is a significant parameter to define the state of the gantry crane, which is a judgment parameter to evaluate the working ability of the gantry crane [45]. The very deflection only considers the deformation caused by the payload and ignores that caused by the dead load. If the deflection exceeds the limit value, the gantry crane cannot work even though the structure is still in an elastic state. Given that, a new DM the called deflection ratio (DR) was proposed to evaluate the level of the working condition of the gantry crane. DR is not a parameter related to the seismic capacity of the gantry crane, but an independent parameter defined by the Chinese code for cranes. They are $1 / 1000,1 / 800$, and $1 / 700$, respectively.

A significant step to develop fragility curves is to define limit states for different structures since their structural features will influence the capacity of the structures. In previous studies, three limit states [29], four limit states [46,47], and five limit states [48] have been recommended to describe the structural performance levels. In this research, three limit states were adopted for the gantry crane according to [29], and they were serviceability (SA), damage control (DC), and collapse prevention (CP), correspondingly. To date, there are two widely used methods to determine the thresholds for different limit states, i.e., pushover analysis [41,49] and incremental dynamic analysis [50,51]. It was proven that the pushover analysis was accurate enough for a structure whose first mode period was less than $2.0 \mathrm{~s}$ [52]. For the example gantry crane, the fundamental period was around $0.56 \mathrm{~s}$. Therefore, pushover analysis was utilized in this study to identify the limit states of the gantry crane. According to the previous description, five groups of thresholds are shown in Table 2 and the cooked data calculated by Equation (5) are also shown in the last three rows of the same table.

Table 2. Thresholds in different limit states. DR, deflection ratio; SA, serviceability; DC, damage control; $\mathrm{CP}$, collapse prevention.

\begin{tabular}{|c|c|c|c|c|c|}
\hline Location & Joint & Midspan & Flexible Leg & Rigid Leg & DR \\
\hline Direction & $X$ & \multicolumn{4}{|c|}{$\mathrm{Y}$} \\
\hline SA (m) & 0.055 & 0.104 & 0.104 & 0.093 & 0.035 (A7) \\
\hline $\mathrm{DC}(\mathrm{m})$ & 0.144 & 0.171 & 0.177 & 0.177 & $0.044(\mathrm{~A} 6)$ \\
\hline $\mathrm{CP}(\mathrm{m})$ & 0.513 & 0.555 & 0.981 & 0.926 & 0.050 (A5) \\
\hline SA (\%) & 0.368 & 0.297 & 1.742 & 1.552 & $0.100(\mathrm{~A} 7)$ \\
\hline DC (\%) & 0.958 & 0.488 & 2.958 & 2.952 & $0.125(\mathrm{~A} 6)$ \\
\hline CP (\%) & 3.422 & 1.586 & 16.358 & 15.436 & 0.143 (A5) \\
\hline
\end{tabular}

The last column shows the thresholds of the deflection ratio. Though they are described by SA, $\mathrm{DC}$, and $\mathrm{CP}$, respectively, they just represent three different working grades, i.e., A7, A6, and A5, respectively. If the deflection ratio exceeds 0.143 , the trolley on the girders will suffer from derailment and cannot operate normally.

Figure 7 shows the curve developed by pushover analysis for the midspan of the trolley girder. Three limit states are shown in Figure 7. The first limit state, serviceability (SA), is described as 
the state in which the gantry crane behaves linearly and can operate with a little repair after the earthquake. Therefore, $0.297 \%$ was taken as the threshold of SA, since it is the end point of the elastic stage. The second limit state is "damage control", and the state means that the gantry crane has suffered significant damage, but has not collapsed. Since the gantry crane is a special equipment with high security requirements, the value of $0.488 \%$ was conservatively chosen as the threshold. The third state called "collapse prevention" represents the state in which the gantry crane begins to collapse. The value of $1.586 \%$ was chosen as the threshold for collapse prevention since the slope of the pushover curve is negative after that point.

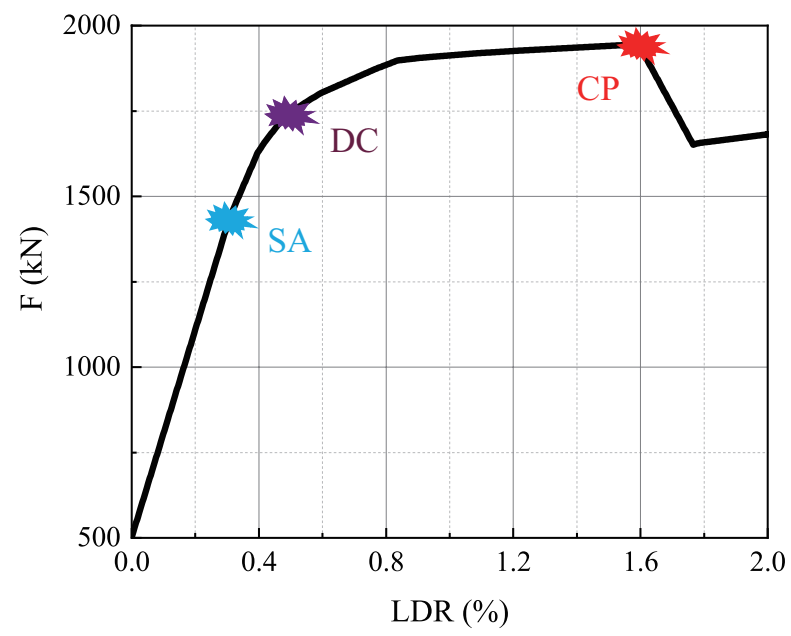

Figure 7. Limit states from pushover analysis. LDR, local displacement ratio.

In summary, the thresholds of $0.297 \%, 0.488 \%$, and $1.586 \%$ were adopted for the SA, DC, and CP of the midspan of the trolley girder in this research, respectively. Besides, the other three groups of limit states were defined by this method, respectively.

\subsection{Solving the Equation of Motion in Nonlinear Time-History Analysis}

Considering a long-span gantry crane under ground motions, the nonlinear discrete equations can be written in the global coordinate system as:

$$
\mathbf{M}(t) \ddot{\mathbf{u}}+\mathbf{C}(t) \dot{\mathbf{u}}+\mathbf{K}(t) \mathbf{u}=-\mathbf{M}(t) \ddot{\mathbf{u}}_{\mathrm{g}}
$$

in which vector $\ddot{u}_{g}$ represents the acceleration of ground motions. $\mathbf{M}(t), \mathbf{C}(t), \mathbf{K}(t)$ are the mass, damping, and stiffness matrices, respectively, all of which are variable with time. $\ddot{u}, \dot{u}, u$ denote the vectors of acceleration, speed, and displacement, respectively.

The equations can be denoted when $t=i+1$ and $t=i$ as:

$$
\begin{gathered}
\mathbf{M}(t) \ddot{\mathbf{u}}_{i+1}+\mathbf{C}(t) \dot{\mathbf{u}}_{i+1}+\mathbf{K}(t) \mathbf{u}_{i+1}=-\mathbf{M}(t) \ddot{\mathbf{u}}_{g_{i+1}} \\
\mathbf{M}(t) \ddot{\mathbf{u}}_{i}+\mathbf{C}(t) \dot{\mathbf{u}}_{i}+\mathbf{K}(t) \mathbf{u}_{i}=-\mathbf{M}(t) \ddot{\mathbf{u}}_{g_{i}}
\end{gathered}
$$

When the time interval is small enough, $\mathbf{M}(t), \mathbf{C}(t), \mathbf{K}(t)$ can be deemed as constant parameters. Therefore, incremental dynamic equations of motion can be obtained by subtracting Equation (7) from Equation (8) as:

$$
\mathbf{M}(t) \Delta \ddot{\mathbf{u}}_{i}+\mathbf{C}(t) \Delta \dot{\mathbf{u}}_{i}+\mathbf{K}(t) \Delta \mathbf{u}_{i}=-\mathbf{M}(t) \Delta \ddot{\mathbf{u}}_{\mathrm{g}_{i}}
$$


Equation (9) is an incremental equilibrium equation with constant mass, damping, and stiffness matrices, which can be solved by the immediate integration method. It can be achieved efficiently in OpenSees.

\section{Selection of Ground Motions}

To consider the uncertainties of seismic records fully, a total of twenty near-field ground motions were selected for the gantry crane in this section, all of which were chosen from the Pacific Earthquake Engineering Research Center (PEER) NGA database [53]. Firstly, given the ground characteristics in which the gantry crane was located, the target spectra developed by the Chinese design response spectrum were input into the database. Then, twenty seismic records were selected among hundreds of candidate ground motions presented by PEER, whose closest distance to rupture plane ( $\left.R_{\text {rup }}\right)$ was less than $20 \mathrm{~km}$. Table 3 shows the detailed acceleration information of the twenty ground motions, and Figure 8 plots the mean spectrum and acceleration spectra of these seismic records. As can be seen in Figure 8, the mean spectrum of the twenty seismic records was in agreement with the target spectrum within an acceptable margin of error.

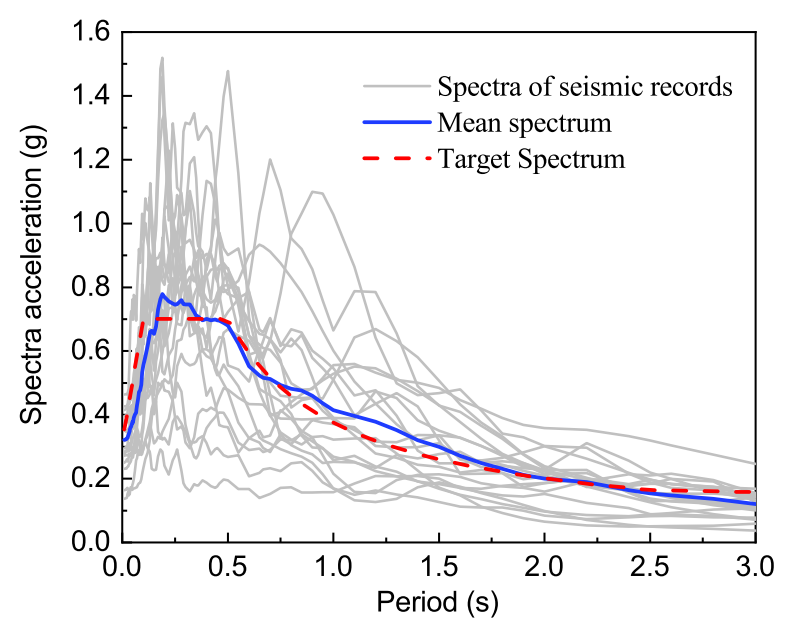

Figure 8. Spectra of seismic records.

Table 3. Summary of selected near-field records. PGA, peak ground acceleration.

\begin{tabular}{|c|c|c|c|c|c|c|}
\hline \multirow{2}{*}{ ID No. } & \multicolumn{3}{|c|}{ Earthquake } & \multirow{2}{*}{ PGA (g) } & \multirow{2}{*}{ Recording Station } & \multirow{2}{*}{$R_{\text {rup }}(\mathbf{k m})$} \\
\hline & Name & Year & Magnitude/M & & & \\
\hline 1 & Imperial Valley 02 & 1940 & 6.95 & 0.28079 & El Centro Array \#9 & 6.09 \\
\hline 2 & Montenegro Yugoslavia & 1979 & 7.10 & 0.18327 & Ulcinj - Hotel Albatros & 4.35 \\
\hline 3 & Irpinia Italy-01 & 1980 & 6.90 & 0.12965 & Bagnoli Irpinio & 8.18 \\
\hline 4 & Corinth Greece & 1981 & 6.60 & 0.23677 & Corinth & 10.27 \\
\hline 5 & Loma Prieta & 1989 & 6.93 & 0.28527 & Gilroy - Historic Bldg. & 10.97 \\
\hline 6 & Cape Mendocino & 1992 & 7.01 & 0.11676 & Fortuna - Fortuna Blvd & 19.95 \\
\hline 7 & Cape Mendocino & 1992 & 7.01 & 0.17738 & Bunker Hill FAA & 12.24 \\
\hline 8 & Landers & 1992 & 7.28 & 0.27358 & Joshua Tree & 11.03 \\
\hline 9 & Northridge 01 & 1994 & 6.69 & 0.34509 & Arleta - Nordhoff Fire Sta & 8.66 \\
\hline 10 & Kobe Japan & 1995 & 6.90 & 0.18455 & Fukushima & 17.85 \\
\hline 11 & Kocaeli Turkey & 1999 & 7.51 & 0.21008 & Arcelik & 13.49 \\
\hline 12 & Duzce Turkey & 1999 & 7.14 & 0.28222 & IRIGM487 & 2.65 \\
\hline 13 & Chi-Chi Taiwan & 1999 & 7.62 & 0.17427 & CHY010 & 19.96 \\
\hline 14 & Duzce Turkey & 1999 & 7.14 & 0.10723 & Lamont 1058 & 0.21 \\
\hline 15 & Hector Mine & 1999 & 7.13 & 0.26546 & Hector & 11.66 \\
\hline 16 & Tottori Japan & 2000 & 6.61 & 0.25177 & SMN001 & 14.42 \\
\hline 17 & Chuetsu-oki Japan & 2007 & 6.80 & 0.18819 & Joetsu Ogataku & 17.93 \\
\hline 18 & Iwate Japan & 2008 & 6.90 & 0.28863 & IWT010 & 16.27 \\
\hline 19 & El Mayor-Cucapah Mexico & 2010 & 7.20 & 0.24849 & Chihuahua & 19.47 \\
\hline 20 & Darfield New Zealand & 2010 & 7.00 & 0.18579 & Canterbury Aero Club & 14.48 \\
\hline
\end{tabular}

Note: $R_{\text {rup }}$ means the closest distance to rupture plane. 


\section{Probabilistic Seismic Performance Assessment of the Gantry Crane}

\subsection{Seismic Input in the Trolley-Travel Direction}

As illustrated above, the probabilistic seismic demand model (PSDM) was built for the gantry crane, and five groups of capacity limit states were constructed to evaluate the performance of the steel structure. In this section, three major working conditions of the gantry crane, i.e., Case 1, Case 2, and Case 3, subjected to ground motions input in the trolley-travel direction are investigated. As mentioned in Section 3, the three working conditions were fully-loaded trolley located in the midspan of the girder, fully-loaded trolley located in cantilever beam close to the flexible legs, and fully-loaded trolley located in cantilever beam close to the rigid legs in sequence. Meanwhile, the three thresholds at the joints of girders and legs were utilized since the seismic records were input in the trolley-travel direction. As 20 ground motions were utilized to take the uncertainties of seismic records into account fully, adequate raw data could be obtained for the probability seismic assessment by incremental dynamic analysis (IDA).

To evaluate the effects of seismic records in the trolley-travel direction completely, the selected ground motions are all input along the trolley-travel direction of the gantry crane in this section. Figure 9 depicts the IDA curves of the gantry crane in terms of the PGA and the maximum LDR value for three working conditions, respectively. This figure also shows the limit states predefined in different colors. In general, it is worth noting that there existed obvious discrepancies between the IDA curves, which indicated that the uncertainties of seismic records were fully investigated in the PSDM. Moreover, when the curves reached the serviceability line in the three working conditions, the values of the minimum PGA were $0.21 \mathrm{~g}, 0.17 \mathrm{~g}$, and $0.18 \mathrm{~g}$, respectively. The data meant the gantry crane in Case 1 had the best seismic performance, while the gantry crane in Case 2 had the worst. However, regarding the other two lines, the gantry crane performed best in Case 2. These results indicated that working conditions had specific effects on the seismic performance of the gantry crane. It should be noted that with the increasing of PGA from $2 \mathrm{~g}$ to $2.5 \mathrm{~g}$, the maximum LDR decreased, and the ground motion's ID number was seven in all cases. The phenomenon happened in all three figures, but was an individual case in 20 examples, respectively.

The data shown in Figure 9 could be transformed in the log-normal space. Regression analysis of $\ln (\mathrm{LDR})$ and $\ln (\mathrm{PGA})$ was utilized to calculate the values of $\mathrm{b}$ and $\mathrm{c}$ in Equation (3). Figure 10 depicts the fragility curves of the gantry crane calculated by Equation (3). As mentioned in [54], the exceedance probabilities should be $63.2 \%, 10 \%$, and $2 \%$ in resisting the frequent, fortification, and rare earthquakes in 50 years, respectively. The maximum accelerations of the design spectra of the frequent, fortification, and rare earthquakes are also drawn in Figure 10, which were developed by considering the site conditions of the gantry crane. The corresponding maximum spectral accelerations were $0.24 \mathrm{~g}, 0.68 \mathrm{~g}$, and $1.2 \mathrm{~g}$. Moreover, the values of logarithmic standard deviation for all the working conditions are listed in Table 4, and Columns 2, 3 and 4 show the deviation values when the ground motions were input in the X-direction (trolley-travel). Generally, the higher the magnitude of the earthquake, the greater the dispersion of the response.

When the gantry crane was in Case 1, as can be seen in Figure 10a, in the frequent earthquakes, the probability of SA was approximately $25 \%$, which met the needs of seismic capacity provided by the Chinese seismic design code for buildings. However, in the fortification and rare earthquakes, the probabilities of DC and CP were $24 \%$ and $3.2 \%$, respectively. Compared with the corresponding exceedance probabilities, the gantry crane, designed by the current Chinese code of cranes, could not meet the requirements. In summary, the example gantry crane could resist the frequent earthquakes excellently, but was designed with inadequate seismic capacity in resisting the fortification and rare earthquakes, and the conclusion is discussed based on Case 1. 


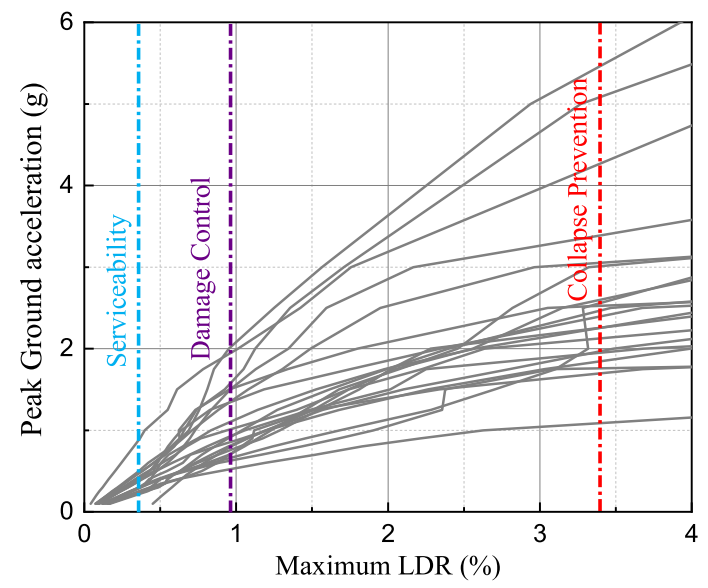

(a) Case 1

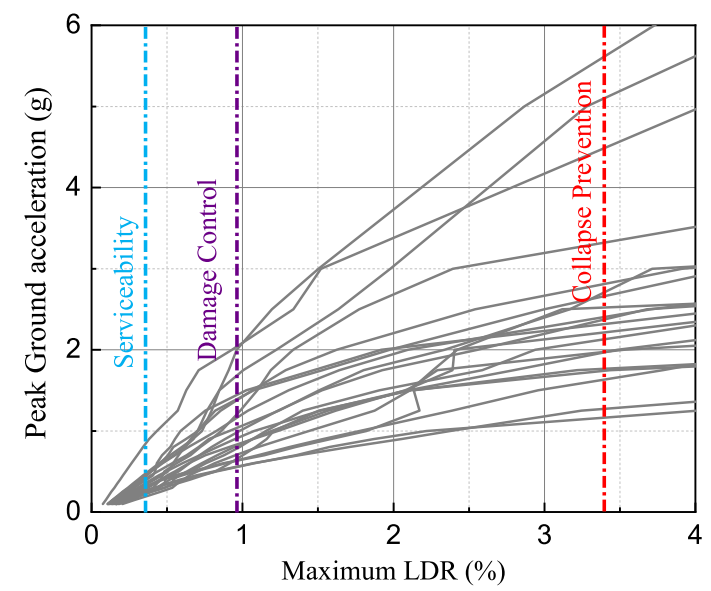

(b) Case 2

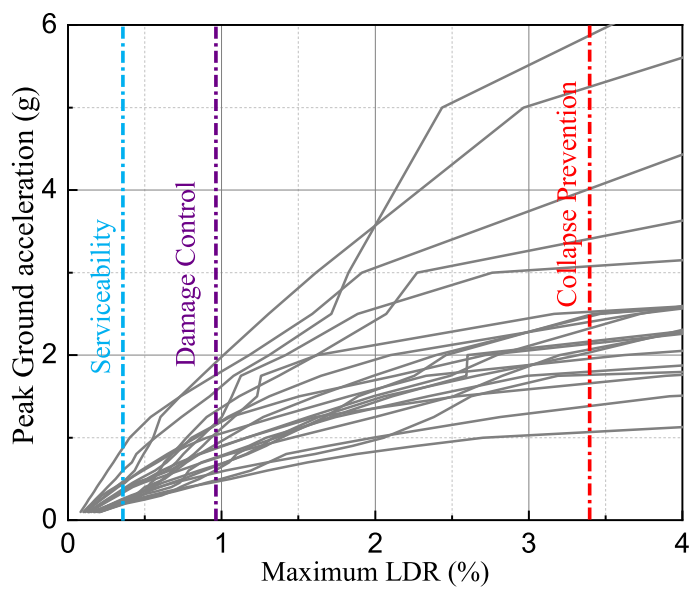

(c) Case 3

Figure 9. IDA curves of the gantry crane in the trolley-travel direction.

Table 4. Logarithmic standard deviation $\left(\beta_{D \mid I M}\right)$ in different working conditions.

\begin{tabular}{|c|c|c|c|c|c|c|c|c|c|}
\hline \multirow{2}{*}{ PGA (g) } & \multicolumn{3}{|c|}{$X$} & \multicolumn{3}{|c|}{$\mathbf{Y}$} & \multirow{2}{*}{ PGA (g) } & \multirow{2}{*}{$\begin{array}{c}\mathrm{X} \\
\text { Case1 }\end{array}$} & \multirow{2}{*}{$\begin{array}{c}\mathrm{Y} \\
\text { Case2 }\end{array}$} \\
\hline & Case1 & Case2 & Case3 & Case1 & Case2 & Case3 & & & \\
\hline 0.10 & 0.454936 & 0.264727 & 0.234379 & 0.037250 & 0.220965 & 0.139335 & 0.025 & 0.016250 & 0.023205 \\
\hline 0.15 & 0.412413 & 0.299522 & 0.263088 & 0.052650 & 0.216653 & 0.130480 & 0.05 & 0.031230 & 0.043446 \\
\hline 0.20 & 0.388634 & 0.322165 & 0.281261 & 0.066388 & 0.214947 & 0.130254 & 0.075 & 0.045095 & 0.061301 \\
\hline 0.25 & 0.370907 & 0.346598 & 0.293267 & 0.078729 & 0.215598 & 0.136213 & 0.10 & 0.057974 & 0.077196 \\
\hline 0.30 & 0.355598 & 0.363478 & 0.304178 & 0.089909 & 0.219283 & 0.147074 & 0.15 & 0.081587 & 0.104340 \\
\hline 0.35 & 0.339620 & 0.370548 & 0.298062 & 0.100329 & 0.226314 & 0.161284 & 0.20 & 0.107767 & 0.126735 \\
\hline 0.40 & 0.325450 & 0.375454 & 0.295775 & 0.110874 & 0.237545 & 0.177406 & 0.25 & 0.131226 & 0.145532 \\
\hline 0.45 & 0.325336 & 0.379089 & 0.303571 & 0.121109 & 0.253745 & 0.196100 & 0.30 & 0.149936 & 0.161768 \\
\hline 0.50 & 0.329362 & 0.381109 & 0.320376 & 0.130370 & 0.274102 & 0.216125 & 0.40 & 0.175138 & 0.193608 \\
\hline 0.60 & 0.346884 & 0.387703 & 0.346963 & 0.146362 & 0.321696 & 0.257031 & & & \\
\hline 0.70 & 0.368891 & 0.397967 & 0.377209 & 0.161454 & 0.368846 & 0.296201 & & & \\
\hline 0.80 & 0.384533 & 0.418047 & 0.398066 & 0.178727 & 0.413262 & 0.333041 & & & \\
\hline 0.90 & 0.404602 & 0.437372 & 0.419609 & 0.199464 & 0.453417 & 0.367543 & & & \\
\hline 1.00 & 0.429109 & 0.454213 & 0.437712 & 0.226996 & 0.485831 & 0.399330 & & & \\
\hline 1.25 & 0.492197 & 0.519413 & 0.501151 & 0.306588 & 0.536291 & 0.459684 & & & \\
\hline 1.50 & 0.484185 & 0.515329 & 0.549734 & 0.371466 & 0.567686 & 0.491422 & & & \\
\hline 1.75 & 0.563078 & 0.595129 & 0.611274 & 0.421608 & 0.580101 & 0.501296 & & & \\
\hline 2.00 & 0.707101 & 0.688463 & 0.694054 & 0.468511 & 0.575675 & 0.490543 & & & \\
\hline 2.50 & 0.771851 & 0.754703 & 0.779756 & 0.717087 & 0.577439 & 0.466495 & & & \\
\hline 3.00 & 0.842577 & 0.807531 & 0.816592 & 0.584265 & 0.617497 & 0.473566 & & & \\
\hline
\end{tabular}


Figure $10 \mathrm{~b}$ shows the fragility curves of the gantry crane in Case 2 . Seventeen percent, $20 \%$, and $2.5 \%$ were the corresponding probabilities of SA, DC, and CP. The first probability was much less than $63.2 \%$, while the probabilities of DC and CP, $20 \%$, and $2.5 \%$, respectively, were larger than the predefined values. The conclusion in Case 1 could also be used to explain the phenomenon in Case 2 .

Finally, the fragility curves of the gantry crane in Case 3 are depicted in Figure 10c. It is worth noting that the corresponding probabilities were surprisingly small, $0.2 \%, 5 \%$, and $0.3 \%$, respectively. All of the data were much less than the exceedance probabilities.

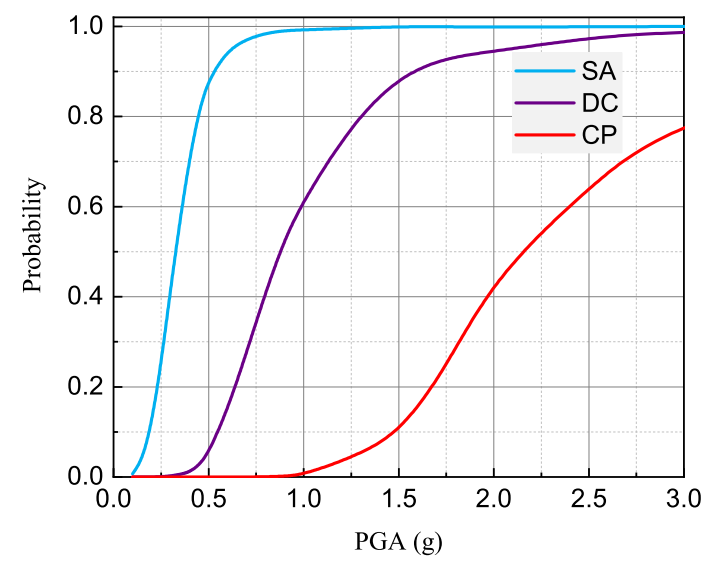

(a) Case 1

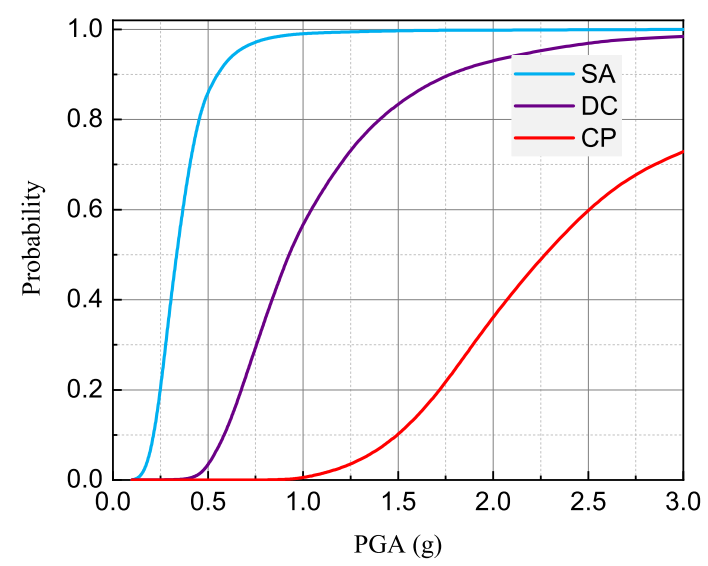

(b) Case 2

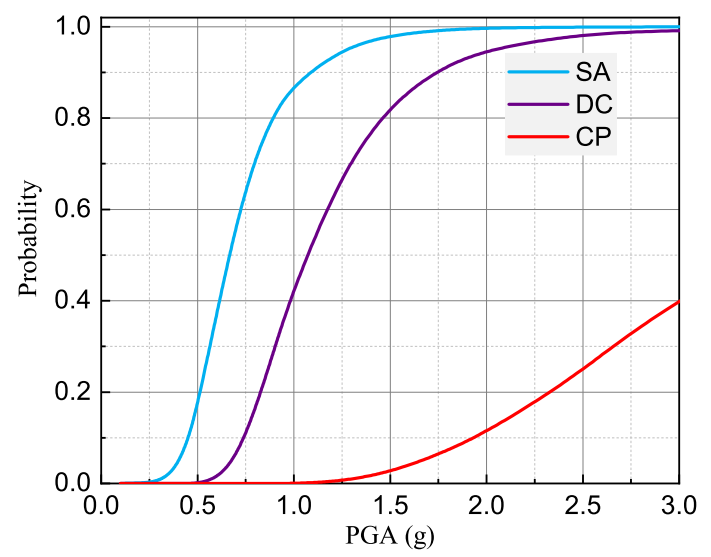

(c) Case 3

Figure 10. Fragility curves of the gantry crane in the trolley-travel direction.

\subsection{Seismic Input in the Vertical Direction}

Different from previous research [55], whose seismic inputs in the horizontal direction were mainly investigated, the response of the trolley girders in the vertical direction was a significant parameter for the gantry crane because of the special working conditions of the gantry crane. Therefore, it was essential to conduct the research on the influence of the ground motions in the vertical direction. As described in Section 5.1, three conditions are also considered in this section. To investigate the capacity of the trolley girder in resisting the vertical deformation completely, the selected ground motions were all input along the vertical direction of the gantry crane.

Figure 11 depicts the IDA curves in terms of the maximum LDR and PGA for three different conditions, respectively. The same as the previous section, regression analysis of $\ln (\mathrm{LDR})$ and $\ln (\mathrm{PGA})$ was also conducted to define the values of the constants $b$ and cin Equation (3), and the dispersion term $\beta_{D \mid I M}$ was calculated as well. According to Figure 11, the conclusion could be drawn that the 
gantry crane had the best seismic performance in Case 3 since the minimum PGAs in Case 3 were the biggest in the three limit states.

Figure 12 gives the performance of the gantry crane subjected to the frequent, fortification, and rare earthquakes based on the fragility curves. The exceedance probabilities should be $63.2 \%, 10 \%$, and $2 \%$, as well.

In Case 1, i.e., Figure 12a, the demand probabilities in resisting the frequent, fortification, and rare earthquakes were very low. In other words, the gantry crane could work continuously in the frequent, fortification, and rare earthquakes input in the vertical direction. The same conclusion could be drawn after investigating the curves in Figures $12 \mathrm{~b}$ and 10c. These facts demonstrated that the trolley girder, one of the major components of the example gantry crane, was designed with adequate seismic capacity in the vertical direction. This conclusion was unexpected considering the heavy payload and long span of the girder.

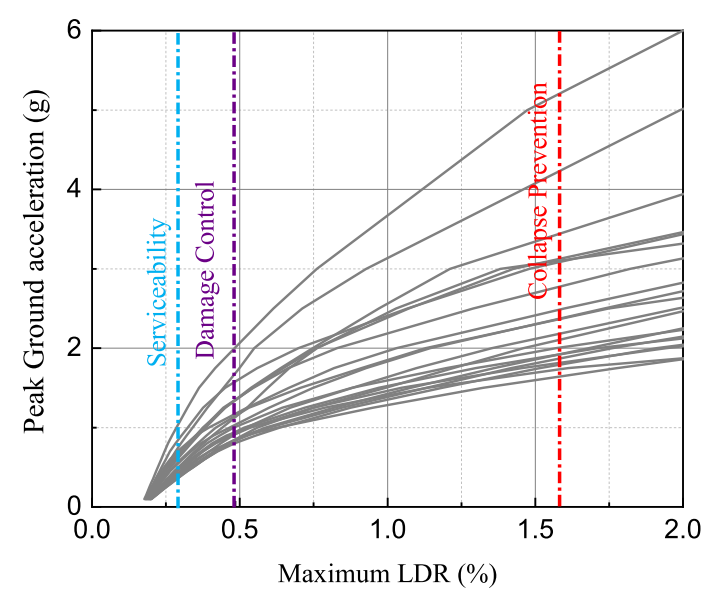

(a) Case 1

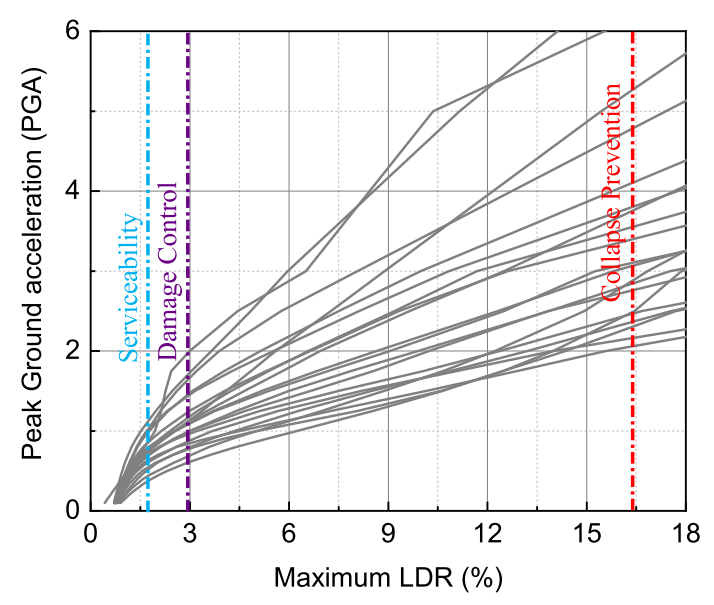

(b) Case 2

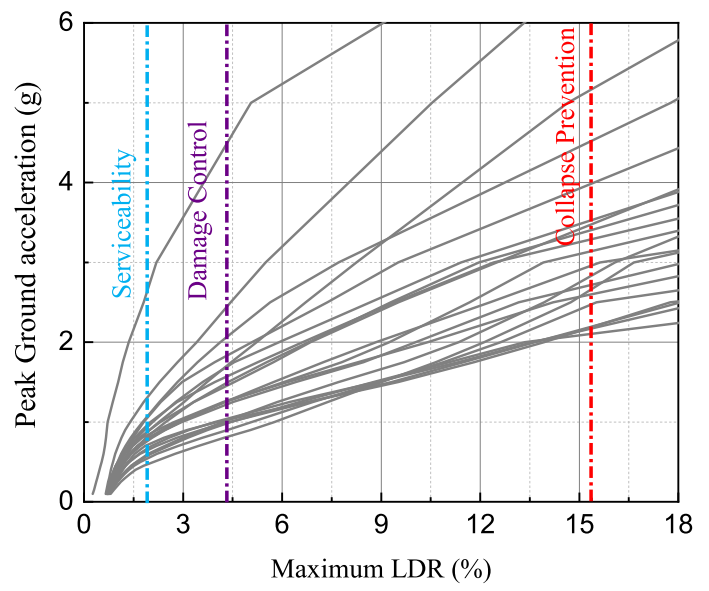

(c) Case 3

Figure 11. IDA curves of the gantry crane in the vertical direction. 


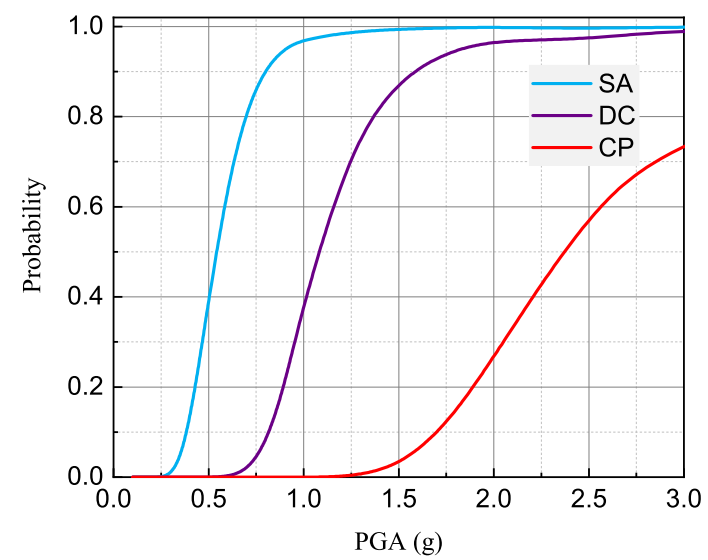

(a) Case 1

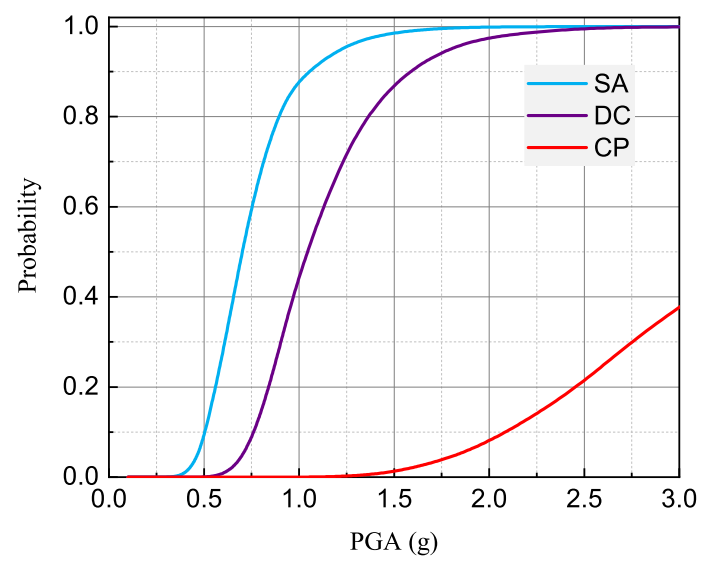

(b) Case 2

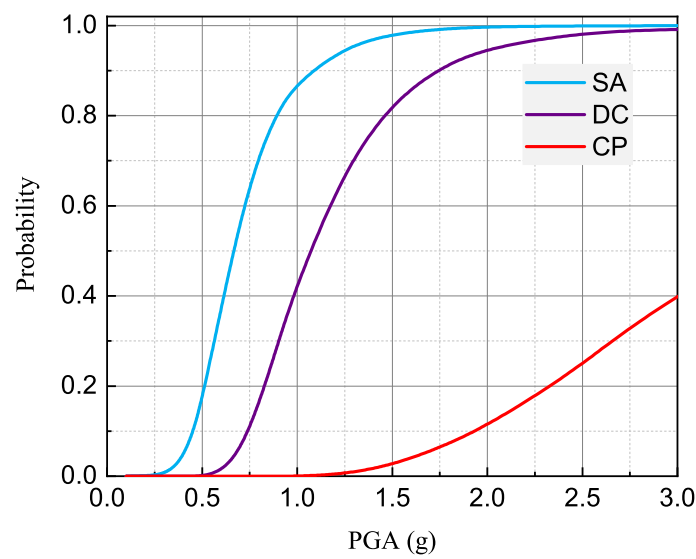

(c) Case 3

Figure 12. Fragility curves of the gantry crane in the vertical direction.

\subsection{Consideration of the Uplift Phenomenon}

Since the cart wheels of the gantry crane are not firmly tied to the ground, it is possible for the wheels to uplift from the rails during an earthquake. However, in this paper, the structure was assumed to be fixed to the crane rails. To evaluate the rationality of this modeling approach, the reaction forces of the flexible and rigid legs during the ground motions were investigated.

Figure 13 shows the probability of the uplift phenomenon of the gantry crane at different earthquake intensities. When the ground motions were input in the trolley-travel direction, an uplift phenomenon occurred while the PGA equaled $3 \mathrm{~g}$ with a probability of $20 \%$. Meanwhile, the minimum PGA was $0.6 \mathrm{~g}$ with a probability of $15 \%$ when the seismic input was in the vertical direction.

It should be noted that when the reaction force was less than zero, the uplift phenomenon was deemed to occur without considering the duration. Therefore, the probability shown in Figure 13 was relatively large and conservative. Given that the safe conclusion could be drawn that in this paper, a fixed boundary condition could simulate the seismic performance of the gantry crane within an acceptable error compared to an uplift-available boundary condition. 


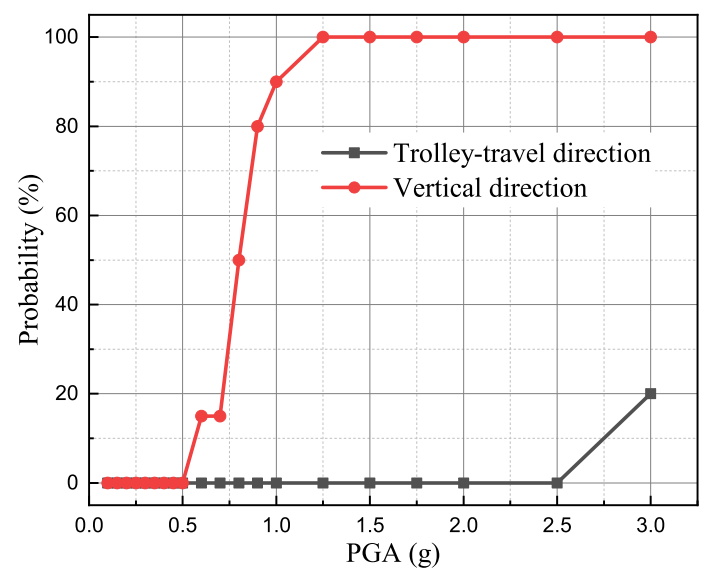

Figure 13. Probability of uplift phenomenon.

\section{Assessment of the Seismic Operating Capacity of the Gantry Crane}

As discussed in the previous section, the trolley girder performed well in nonlinear analyses. To pay more attention to the seismic capacity of the operating gantry crane, another assessment is carried out in this section to conduct the seismic performance of the trolley girder in the elastic stage, which is one of the most essential performance indexes. The reason is discussed in Section 3: if the reflection ratio exceeds certain values (shown in Table 4), the trolley on the girders cannot work normally. It should be noted that the girders were in the elastic stage during the whole research in this section. To consider the influence of the direction of the ground motions fully, two directions were taken into consideration, and they were the trolley-travel direction and the vertical direction, respectively.

\subsection{Seismic Input in the Trolley-Travel Direction}

In this section, the seismic records were input in the trolley-travel direction. The gravity load and the dead load of the gantry crane itself, which could cause the initial deflection, were ignored. The weight of the fully-loaded trolley was regarded as the only payload. Figure 14a shows the IDA curves of the gantry crane in terms of the PGA and the maximum DR for the seismic records input in the trolley-travel direction. With respect to the figure, most of the IDA curves were linear because the deflection ratio was defined in the elastic state.

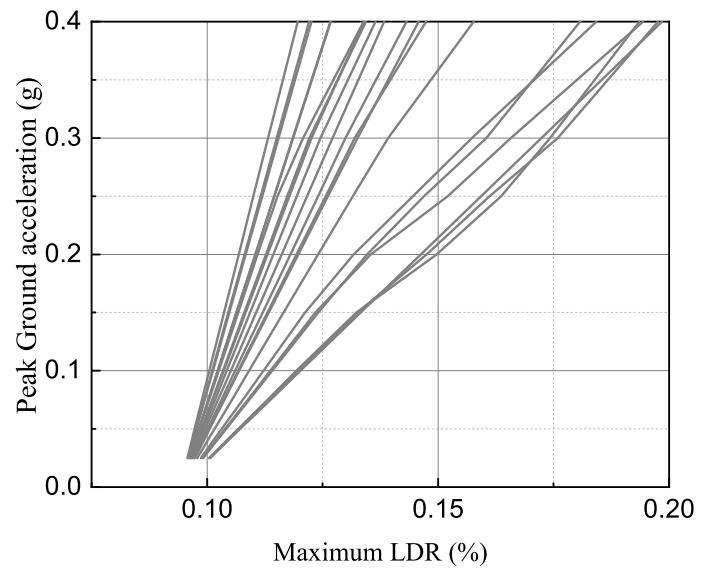

(a) Seismic records input in the trolley-travel direction

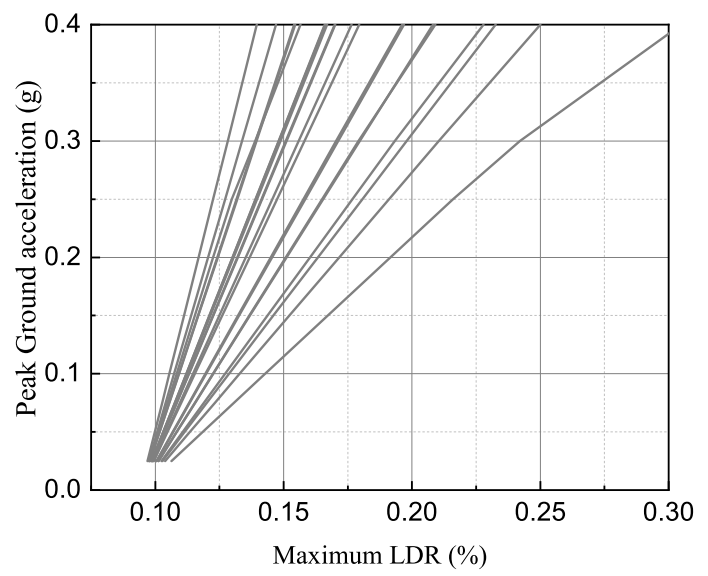

(b) Seismic records input in the vertical direction

Figure 14. IDA curves of the gantry crane.

Figure 15a depicts the fragility curves of the gantry crane in the A7, A6, and A5 states, respectively. Since no fragility analysis was conducted in previous studies, a new definition should be proposed 
to quantitatively evaluate the seismic capacity of the gantry crane. In this study, the value of the acceleration when the exceedance probability equaled $50 \%$ was defined as the seismic operating peak ground acceleration (OSPGA), which was utilized to measure the mean seismic operating capacity of the steel structure. In this case, the OSPGA could be obtained as $0.04 \mathrm{~g}, 0.23 \mathrm{~g}$, and $0.36 \mathrm{~g}$, respectively. They were the maximum PGA that the gantry crane could work normally in the A7, A6, and A5 states, respectively. These data could be references for the design of the gantry cranes located in an earthquake-prone area. Moreover, they could also be utilized to assess the condition of the gantry crane after an earthquake.

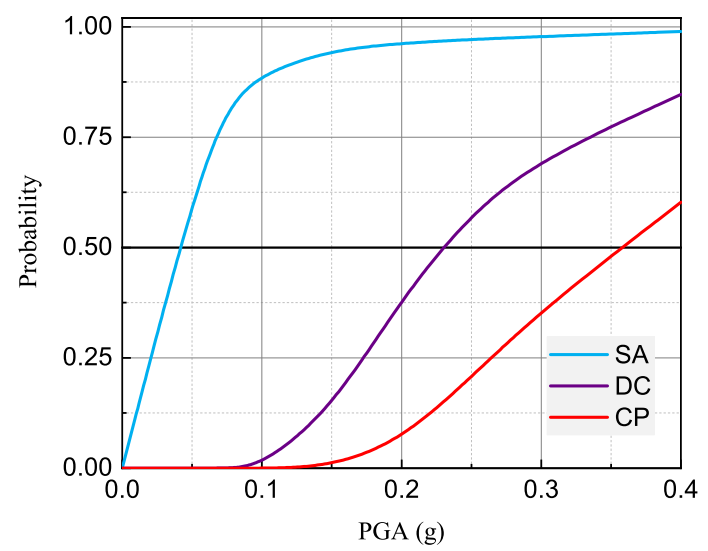

(a) Seismic records input in the trolley-travel direction

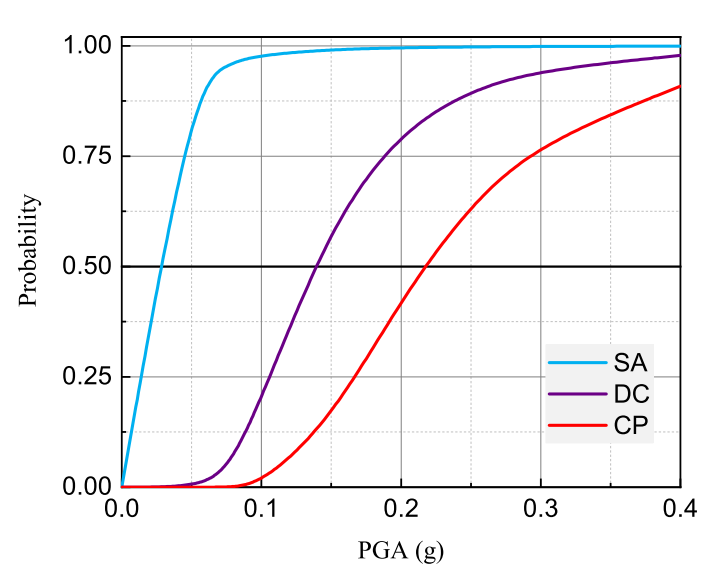

(b) Seismic records input in the vertical direction

Figure 15. Fragility curves of the gantry crane.

\subsection{Seismic Input in the Vertical Direction}

In this section, the seismic records are input in the vertical direction. The gravity load and dead load of the gantry crane itself were ignored as well. The weight of the fully-loaded trolley was regarded as the only payload. Figure 14b shows the IDA curves of the gantry crane in terms of the PGA and the maximum DR for the seismic records input in the vertical direction. Most of the IDA curves were linear, and only two IDA curves slightly behaved nonlinearly.

Figure $15 \mathrm{~b}$ depicts the fragility curves of the gantry crane in the A7, A6, and A5 states, respectively. As defined above, the OSPGA could be obtained as $0.02 \mathrm{~g}, 0.13 \mathrm{~g}$, and $0.21 \mathrm{~g}$, respectively. Compared with the OSPGA in the trolley-travel direction, all the OSPGA data in the vertical direction were smaller than those in the trolley-travel direction. This fact revealed that even though the earthquake in the vertical direction could bring negligible structural damage to the gantry crane, it could determine the working grade of the gantry crane to a great extent.

\section{Conclusions}

This paper investigated the seismic fragility of the gantry crane by utilizing the probabilistic seismic demand model (PSDM). The local displacement ratio (LDR) was specially formulated to serve as the seismic demand measure (DM), and the peak ground acceleration (PGA) was chosen as the IM. Pushover analysis was performed to define four groups of capacity limit states for the gantry crane, and the other group of three parameters was defined by [45]. Moreover, the IDAs were used to obtain the raw data for the PSDM. Then, the fragility curves for different limit states were developed based on IDAs. Finally, the operating seismic capacity of the gantry crane was further investigated. Based on the results above, the following major conclusions can be drawn:

- It was quite necessary to conduct the fragility analysis considering the location of the gantry crane, and seismic performance should be investigated in the design stage according to the results shown above. 
- The horizontal component of the ground motions was more threatening to the structural failure of the gantry crane compared to the vertical component.

- Uplift events may occur when the horizontal PGA was more than $2.5 \mathrm{~g}$ or the vertical PGA was more than $0.6 \mathrm{~g}$. It was reasonable in this paper to utilize a fixed gantry crane model to simulate the seismic performance of the structure within an acceptable error.

- This study provided the framework for quantifying the seismic operating capacity of gantry crane under earthquakes considering seismic uncertainties, which is essential in the fast estimation of the gantry crane status during and after an earthquake.

Author Contributions: Conceptualization, Q.P.; supervision, W.C.; methodology, H.J.; software, Q.P.; writ draft preparation, Q.P.; writ and editing, H.J. and P.G. All authors have read and agreed to the published version of the manuscript.

Funding: The research for this paper was funded by the Science and Technology Plan of Sichuan Science and Technology Department (No. 2019YJ0243), the National Science Foundation of China (No. 51675450 and No. 51308465), and the Postdoctoral Science Foundation of China (No. 2015M580031). The authors would like to express their sincere gratitude to all the sponsors for the financial support.

Acknowledgments: The research for this paper was supported partially by the Science and Technology Plan of Sichuan Science and Technology Department (No. 2019YJ0243), the National Science Foundation of China (No. 51675450 and No. 51308465), and the Postdoctoral Science Foundation of China (No. 2015M580031). The authors would like to express their sincere gratitude to all the sponsors for the financial support.

Conflicts of Interest: The authors declare no conflict of interest.

\section{References}

1. Manafpour, A.R.; Jalilkhani, M. A Rapid Analysis Procedure for Estimating the Seismic Collapse Capacity of Moment Resisting Frames. J. Earthq. Eng. 2019, 1-20. [CrossRef]

2. Shahi, R.; Lam, N.; Gad, E.; Wilson, J.; Watson, K. Seismic performance behavior of cold-formed steel wall panels by quasi-static tests and incremental dynamic analyses. J. Earthq. Eng. 2017, 21, 411-438. [CrossRef]

3. Hoffmann, K. Development of design of ship-to-shore container cranes: 1959-2004. In International Symposium on History of Machines and Mechanisms; Springer: London, UK, 2004; pp. 229-242.

4. Soderberg, E.; Jordan, M. Seismic response of jumbo container cranes and design recommendations to limit damage and prevent collapse. In Proceedings of the ASCE Ports 2007 Conference, San Diego, CA, USA, 25-28 March 2007.

5. Soderberg, E.; Hsieh, J.; Dix, A. Seismic guidelines for container cranes. In Proceedings of the TCLEE 2009, Oakland, CA, USA, 28 June-1 July 2009.

6. Dinevski, D.; Oblak, M.; Novak, A. Experimental Verification of the Container Crane Natural Frequencies; WIT Press: Boston, MA, USA, 1970; Volume 17.

7. Kanayama, T. Large shaking table test of a container crane by strong ground excitation. In Proceedings of the ASME/JSME PVP 1998, San Diego, CA, USA, 26-30 July 1998.

8. Kanayama, T. A study on the dynamic behavior of container cranes under strong earthquakes. In Proceedings of the ASME/JSME PVP 1998, San Diego, CA, USA, 26-30 July 1998.

9. Tanabe, T.; Etou, T.; Yamamoto, S.; Sugano, T.; Miyata, M.; Kashiwazaki, A. Experiment on behavior of container cranes during strong earthquakes. Trans. Jpn. Soc. Mech. Eng. Ser. C 2000, 66, 205-212. [CrossRef]

10. Jacobs, L.D.; Kosbab, B.D.; Leon, R.T.; DesRoches, R. Seismic behavior of a jumbo container crane including uplift. Earthq. Spectra 2011, 27, 745-773. [CrossRef]

11. Kosbab, B.D. Seismic Performance Evaluation of Port Container Cranes Allowed to Uplift. Ph.D. Thesis, Georgia Institute of Technology, Atlanta, GA, USA, 2010.

12. Li, Z.; Wang, G.; Wang, D.; Hu, J. Testing methods on dynamics behavior of jumbo container cranes under seismic loads. J. Wuhan Univ. Technol. 2013, 8. [CrossRef]

13. Sagirli, A.; Azeloglu, C.O. Investigation of the Dynamic Behaviors of Cranes under Seismic Effects with Theoretical and Experimental Study. Adv. Mater. Res. 2012, 445, 6.

14. Yazici, H.; Azeloglu, C.O.; Kucukdemiral, I.B. Active vibration control of container cranes against earthquake by the use of delay-dependent $\mathrm{H} \infty$ controller under consideration of actuator saturation. J. Low Freq. Noise Vib. Act. Control. 2014, 33, 289-316. [CrossRef] 
15. Azeloglu, C.O.; Sagirli, A. Active Vibration Control of Container Cranes against Earthquake by the Use of LMI Based Mixed $H_{2} / H_{\infty}$ State-Feedback Controller. Shock Vib. 2015, 2015, 589289.

16. Azeloglu, C.O.; Sagirli, A.; Edincliler, A. Vibration mitigation of nonlinear crane system against earthquake excitations with the self-tuning fuzzy logic PID controller. Nonlinear Dyn. 2016, 84, 1915-1928. [CrossRef]

17. Sagirli, A.; Azeloglu, C.O.; Guclu, R.; Yazici, H. Self-tuning fuzzy logic control of crane structures against earthquake induced vibration. Nonlinear Dyn. 2011, 64, 375-384. [CrossRef]

18. Lupoi, G.; Franchin, P.; Lupoi, A.; Pinto, P.E. Seismic fragility analysis of structural systems. J. Eng. Mech. 2006, 132, 385-395. [CrossRef]

19. Rosowsky, D.V.; Ellingwood, B.R. Performance-based engineering of wood frame housing: Fragility analysis methodology. J. Struct. Eng. 2002, 128, 32-38. [CrossRef]

20. Jia, H.; Zhao, J.; Li, X. Probabilistic pounding analysis of high-pier continuous rigid frame bridge with actual site conditions. Earthq. Struct. 2018, 15, 193-202.

21. Asgarian, B.; Sadrinezhad, A.; Alanjari, P. Seismic performance evaluation of steel moment resisting frames through incremental dynamic analysis. J. Constr. Steel Res. 2010, 66, 178-190. [CrossRef]

22. Fattahi, F.; Gholizadeh, S. Seismic fragility assessment of optimally designed steel moment frames. Eng. Struct. 2019, 179, 37-51. [CrossRef]

23. Mander, J.B.; Dhakal, R.P.; Mashiko, N.; Solberg, K.M. Incremental dynamic analysis applied to seismic financial risk assessment of bridges. Eng. Struct. 2007, 29, 2662-2672. [CrossRef]

24. Jia, H.; Lan, X.; Luo, N.; Yang, J.; Zheng, S.; Zhang, C. Nonlinear Pounding Analysis of Multispan and Simply Supported Beam Bridges Subjected to Strong Ground Motions. Shock Vib. 2019, 2019. [CrossRef]

25. Jia, H.; Lan, X.; Zheng, S. Assessment on required separation length between adjacent bridge segments to avoid pounding. Soil Dyn. Earthq. Eng. 2019, 120, 398-407. [CrossRef]

26. Tian, L.; Pan, H.; Ma, R. Probabilistic seismic demand model and fragility analysis of transmission tower subjected to near-field ground motions. J. Constr. Steel Res. 2019, 156, 266-275. [CrossRef]

27. Dolsek, M. Incremental dynamic analysis with consideration of modeling uncertainties. Earthq. Eng. Struct. Dyn. 2009, 38, 805-825. [CrossRef]

28. Lee, T.; Mosalam, K.M. Seismic demand sensitivity of reinforced concrete shear-wall building using FOSM method. Earthq. Eng. Struct. Dyn. 2005, 34, 1719-1736. [CrossRef]

29. Kwon, O.; Elnashai, A. The effect of material and ground motion uncertainty on the seismic vulnerability curves of RC structure. Eng. Struct. 2006, 28, 289-303. [CrossRef]

30. Padgett, J.E.; DesRoches, R. Sensitivity of seismic response and fragility to parameter uncertainty. J. Struct. Eng. 2007, 133, 1710-1718. [CrossRef]

31. Mazzoni, S.; McKenna, F.; Scott, M.H.; Fenves, G.L. OpenSees command language manual. Pac. Earthq. Eng. Res. (PEER) Cent. 2006, 264.

32. Mckenna, F.T. Object-Oriented Finite Element Programming: Frameworks for Analysis, Algorithms and Parallel Computing. Ph.D. Thesis, University of California, Berkeley, CA, USA, 1999.

33. Scott, M.H.; Fenves, G.L.; McKenna, F.; Filippou, F.C. Software patterns for nonlinear beam-column models. J. Struct. Eng. 2008, 134, 562-571. [CrossRef]

34. Wang, D.; Wang, G.; Xiong, Y.; Hu, J. Analysis of Nonlinear Dynamic Second-Order Effect of a Large-Scale Container Crane Under Seismic Excitations. In Vibration Engineering and Technology of Machinery; Springer: London, UK, 2015; pp. 889-899.

35. Agency, F.E.M. Prestandard and Commentary for the Seismic Rehabilitation of Buildings; American Society of Civil Engineers (ASCE): Reston, VA, USA, 2000.

36. Cornell, C.A.; Jalayer, F; Hamburger, R.O.; Foutch, D.A. Probabilistic basis for 2000 SAC federal emergency management agency steel moment frame guidelines. J. Struct. Eng. 2002, 128, 526-533. [CrossRef]

37. Wen, Y.; Ellingwood, B.R.; Bracci, J.M. Vulnerability Function Framework for Consequence-based Engineering; MAE Center Report 04-04; MAE Center: Urbana, IL, USA, 2004.

38. Vamvatsikos, D.; Cornell, C.A. Incremental dynamic analysis. Earthq. Eng. Struct. Dyn. 2002, 31, 491-514. [CrossRef]

39. Vamvatsikos, D.; Cornell, C.A. Applied incremental dynamic analysis. Earthq. Spectra 2004, 20, 523-553. [CrossRef]

40. Zentner, I. A general framework for the estimation of analytical fragility functions based on multivariate probability distributions. Struct. Saf. 2017, 64, 54-61. [CrossRef] 
41. Kinali, K.; Ellingwood, B.R. Seismic fragility assessment of steel frames for consequence-based engineering: A case study for Memphis. TN Eng. Struct. 2007, 29, 1115-1127. [CrossRef]

42. Ramamoorthy, S.K.; Gardoni, P.; Bracci, J.M. Probabilistic demand models and fragility curves for reinforced concrete frames. J. Struct. Eng. 2006, 132, 1563-1572. [CrossRef]

43. Casciati, F.; Cimellaro, G.P.; Domaneschi, M. Seismic reliability of a cable-stayed bridge retrofitted with hysteretic devices. Comput. Struct. 2008, 86, 1769-1781. [CrossRef]

44. Kazantzi, A.; Righiniotis, T.; Chryssanthopoulos, M. Fragility and hazard analysis of a welded steel moment resisting frame. J. Earthq. Eng. 2008, 12, 596-615. [CrossRef]

45. Zhang, Z.; Wang, J. Crane Design Mannual; China Railway Publishing House: Beijing, China, 2013.

46. Comartin, C.D.; Niewiarowski, R.W.; Rojahn, C. Seismic Evaluation and Retrofit of Concrete Buildings; Seismic Safety Commission, State of California: West Sacramento, CA, USA, 1996; Volume 1.

47. Council, B.S.S. NEHRP Guidelines for the Seismic Rehabilitation of Buildings; FEMA-273; Federal Emergency Management Agency: Washington, DC, USA, 1997; pp. 2-12.

48. Reinhorn, A.; Barron-Corverra, R.; Ayala, A. Spectral evaluation of seismic fragility of structures. In Proceedings of the ICOSSAR, Newport Beach, CA, USA, 17-22 June 2001; Volume 2001.

49. Foutch, D.A.; Yun, S.Y. Modeling of steel moment frames for seismic loads. J. Constr. Steel Res. 2002, 58, 529-564. [CrossRef]

50. Brunesi, E.; Nascimbene, R.; Parisi, F.; Augenti, N. Progressive collapse fragility of reinforced concrete framed structures through incremental dynamic analysis. Eng. Struct. 2015, 104, 65-79. [CrossRef]

51. Billah, A.M.; Alam, M.S. Statistical distribution of seismic performance criteria of retrofitted multi-column bridge bents using incremental dynamic analysis: A case study. Bull. Earthq. Eng. 2013, 11, 2333-2362. [CrossRef]

52. Krawinkler, H.; Seneviratna, G. Pros and cons of a pushover analysis of seismic performance evaluation. Eng. Struct. 1998, 20, 452-464. [CrossRef]

53. Ranf, R.T.; Eberhard, M.O.; Berry, M.P. Pacific Earthquake Engineering Research Center; University of California: Berkeley, CA, USA, 2001.

54. Ministry of Construction of China. Code for Seismic Design of Buildings; GB50011; Ministry of Construction of China: Beijing, China, 2011.

55. Silwal, B.; Ozbulut, O.E. Aftershock fragility assessment of steel moment frames with self-centering dampers. Eng. Struct. 2018, 168, 12-22. [CrossRef]

(C) 2020 by the authors. Licensee MDPI, Basel, Switzerland. This article is an open access article distributed under the terms and conditions of the Creative Commons Attribution (CC BY) license (http://creativecommons.org/licenses/by/4.0/). 